\title{
Seismic behaviour of cross vaults with different brick pattern
}

\author{
M. Alforno ${ }^{1}$ D $\cdot$ F. Venuti ${ }^{1} \cdot$ A. Monaco ${ }^{1} \cdot$ C. Calderini ${ }^{2}$
}

Received: 23 July 2021 / Accepted: 2 February 2022

(c) The Author(s) 2022

\begin{abstract}
Cross masonry vaults are common structural elements in historical buildings. They are largely diffused in all European countries, including those characterized by higher levels of seismicity. Although they have been constructed for centuries, they represent some of the most vulnerable elements of traditional architecture, especially with reference to horizontal loads. The understanding of their structural behaviour under seismic loading is a crucial aspect for the accurate assessment of the safety of historical buildings. In the present work, the seismic response of cross masonry vaults is analysed through the Finite Element Method (FEM) and static non-linear analyses considering the effect of different brick patterns and boundary conditions. A simplified micro-modelling approach is adopted for the generation of the FEM models and two different brick arrangements are considered, i.e., radial bricks and diagonal bricks, which are the most widespread in European cross vaults. Two different boundary conditions are assumed in order to simulate a vault with and without lateral confinement. Static non-linear analyses are performed by monotonically incrementing a lateral acceleration until collapse. Results are analysed in terms of maximum load factor, stiffness, ductility, crack pattern and damage mechanisms. The analysis of the results shows that not only boundary conditions, but also the brick pattern strongly influences the vault seismic response both in terms of stiffness and ductility as well as in terms of global capacity.
\end{abstract}

Keywords Cross vaults $\cdot$ Brick pattern $\cdot$ FEM model $\cdot$ Push-over analysis $\cdot$ Seismic behaviour

\section{Introduction}

Vaulted structures have been constructed for centuries and are widely diffused in many heritage buildings in high seismic risk European countries (Gaetani et al. 2016; Carfagnini et al. 2018; Bertolesi et al. 2019). However, recent earthquakes have demonstrated that these structures are very vulnerable, especially in case of imperfect design or badly executed interventions (Gaetani et al. 2017). Their seismic response is relevant at both local

M. Alforno

marco.alforno@polito.it

1 Department of Architecture and Design, Politecnico di Torino, Turin, Italy

2 Department of Civil, Chemical and Environmental Engineering, University of Genoa, Genoa, Italy 
and global scale. At local scale, their collapse may produce damage and injuries. At global scale, they can highly affect the collapse mechanism of the whole building, because they are heavy horizontal elements (if compared to timber floors) that during the seismic events may produce large horizontal thrusts on the lateral walls. For these reasons, the assessment of the seismic vulnerability of masonry vaults is crucial for the safeguard of ancient masonry buildings.

In this regard, it is necessary to evaluate the ultimate displacement and load bearing capacity of vaults under horizontal loading. Despite several efforts have already been done to understand the seismic response of arches and barrel vaults (Oppeneheim 1992; Clemente 1998; De Luca et al. 2004; De Lorenzis et al. 2007; De Jong et al. 2008), masonry cross vaults have been only rarely studied. Such vaults exhibit a highly complex threedimensional response that make their seismic analysis quite difficult (Rossi et al. 2016, 2020). Moreover, they can be built according to different brick patterns, further increasing the complexity of the problem.

Several approaches have been used in the literature for the analysis of historical masonry vaults, which are useful to highlight the numerous aspects to be considered in the global assessment of their behaviour. The collapse mechanisms can be studied according to two main approaches, namely incremental analysis and limit analysis. In the first case, nonlinear static and dynamic analyses can be conducted through an iterative procedure aimed at following step-by-step the evolution of the equilibrium conditions. In the second case, Heyman's assumptions (rigid no-tension model) are adopted in form of static or kinematic theorem for finding the collapse multiplier that provides the optimal solution (D'Ayala and Tomasoni 2011; Riveiro et al. 2011; Block and Lachauer 2014; Mousavian and Casapulla 2019; Nodargi and Bisegna 2021). These two analysis approaches can be then applied to different modelling strategies, which can be usefully classified according to D'Altri et al. (2019) into four categories: block-based, continuum, macroelement and geometry-based models.

In block-based strategies, masonry is modelled as assembly of blocks and joints (mortar or dry joints), allowing the actual masonry texture to be modelled, directly controlling the anisotropy and the failure patterns of the material. The interaction between blocks can be then simulated by different approaches: the use of interface elements and the definition of analytical contact properties are among the most widely adopted. It can be noteworthy to mention the increasing interest for this kind of approach also in engineering application fields related to preliminary forensic investigations of damaged masonry constructions undergoing collapse mechanisms, especially introducing the simplification of bi-dimensional structural scheme (Palmisano and Perilli 2017; Olmati et al. 2019).

In continuum approaches, masonry is modelled as a continuum deformable body and, therefore, its anisotropic mechanical behaviour has to be included in suitable homogeneous constitutive laws, whose definition still represents a challenging task especially in the damaged post-elastic regime. Conversely, such approach allows for less computationally demanding models thanks to the mesh size, which could be significantly higher than the block dimension.

Macroelement models mainly apply to masonry panels and walls and are the most widely diffused strategies for the seismic assessment of masonry structures. In this regard, some approaches have been also formulated for the simplified modelling of vaults when they are present as floor system in the masonry building, the knowledge of their seismic response being crucial for predicting a reliable distribution of horizontal forces. To this end, some authors found that the evaluation of an equivalent plane element replacing the vaulted floor can be an effective solution, allowing some vault typologies to be included in the global seismic analysis 
in form of isotropic or orthotropic membranes, assessing an equivalent elastic stiffness in order to idealize these horizontal structural elements (Cattari et al. 2008; Marseglia et al. 2020).

Finally, in geometry-based models the structure is intended as a rigid body and, therefore, the analysis input basically consists in the geometric features and the load conditions: the equilibrium and/or the collapse mechanism is assessed through the limit analysis theorems.

In this paper a block-based approach is adopted in order to predict the seismic behaviour of masonry cross vaults. The numerical approach is particularly suitable because of the limited possibility to perform full-scale laboratory tests, which represent a relevant validation tool when available. Block-based models are the most accurate strategy especially for investigations on large-scale structures with irregular and complex geometry, as in the current analysis, and the contact-based approach adopted in this work proved to be the most effective tool in the literature (D'Altri et al. 2019). Discrete Element Method (DEM) and Finite Element Method (FEM) models are among the most widely adopted block-based numerical approaches and several research papers aim at discussing pros and cons given by their application to specific case-studies (Giamundo et al. 2014; Sarhosis et al. 2018). In particular, DEM models are developed by the discretization of the vault into rigid or elastic blocks connected by means of non-linear interfaces, commonly modelled with elasto-plastic behaviour with softening branch, which represents the degradation of contact (McInerney and DeJong 2015; Lengyel 2017; Lengyel and Németh 2019; Foti et al. 2018). Conversely, FEM models generally assume elastic and cracked behaviour of masonry by means of several approaches such as macro- or micro-modelling and isotropic or anisotropic constitutive laws (Gaetani et al. 2017, 2021; Milani et al. 2016, 2017, 2019). In this frame, the present work is focused on the modelling of cross vaults of ideal geometry through the simplified micro-modelling approach in the framework of FEM (Alforno et al. 2020, 2021a, 2021b). This modelling approach has already been used by the authors and successfully validated with physical in-scale models (Alforno et al. 2021a). More in detail, in simplified micro-modelling approach, expanded units are modelled as continuum elements, while mortar joints and unit/mortar interfaces are lumped into an "average" interface. The use of micro-mechanical models allows to simulate block-toblock interactions and therefore the real interlocking of bricks. In this work, two different brick arrangements are considered, i.e., radial and diagonal pattern, which are the ones most found in European cross vaults (Fig. 1). Moreover, different boundary conditions are taken into consideration in order to simulate a vault with and without lateral confinement. In particular, the presence of confinement can be easily related to a cross vault of a lateral nave of a church or of a portico. Conversely, the absence of lateral boundaries is used for analysing vaults with not efficient confining structures. Static non-linear pushover analyses are performed by monotonically incrementing a lateral acceleration until collapse. Results are analysed in terms of maximum load factor, stiffness, ductility, crack pattern and collapse mechanisms.

The paper is developed in three subsequent sections: in Sect. 2 the model is described in terms of geometry, boundary conditions, applied load and numerical approach; results of the parametric analysis are described and commented in Sect. 3, while Sect. 4 outlines some conclusions. 


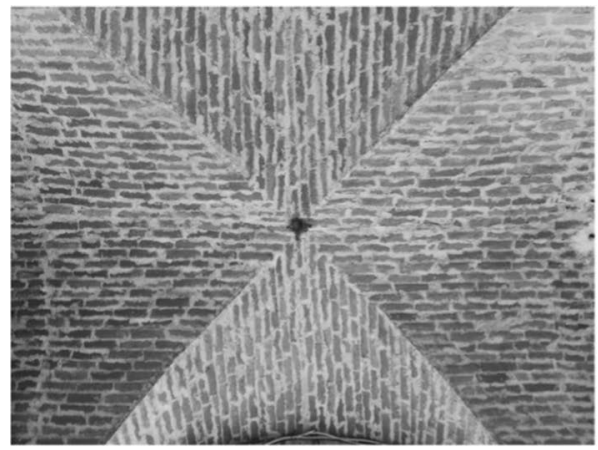

(a)

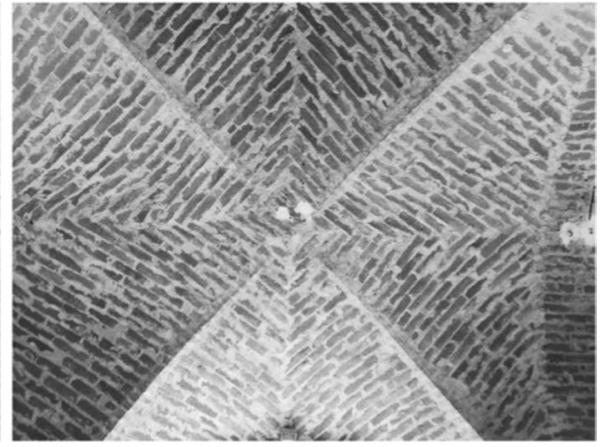

(b)

Fig. 1 Radial (a) and diagonal (b) brick pattern in real cross vaults (Palazzata in Vicoforte - Italy)

\section{Description of the model}

In this section the main features of the FEM model are described in terms of geometry, mechanical parameters of materials and interface properties, and numerical approach. Moreover, the load cases and the boundary conditions are illustrated, as well as the summary of performed parametric analyses.

\subsection{Geometry and mechanical features}

The geometry of all the vaults is generated with the modelling software Rhinoceros and derives from the intersection of two semi-circular barrel vaults with a net span of approximately $3.1 \mathrm{~m}$. and a lowered rise of $1.175 \mathrm{~m}$. The volume is discretized into bricks of size $6 \times 12 \times 24 \mathrm{~cm}$. The shape of the interlocked bricks along the diagonal arches is idealized and simplified. Four rigid corner supports are modelled at the base of the vault. Two different brick patterns are modelled, namely those which follow radial (R) and diagonal (D) pattern, respectively (Fig. 2). The vault with the radial pattern is composed of 1208 bricks, whereas the diagonal vault is made of 1345 bricks.

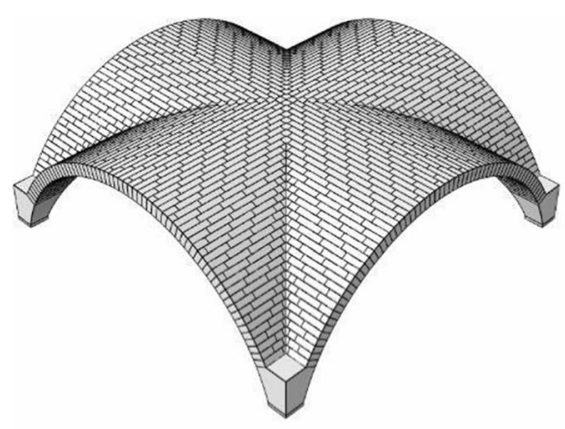

(a)

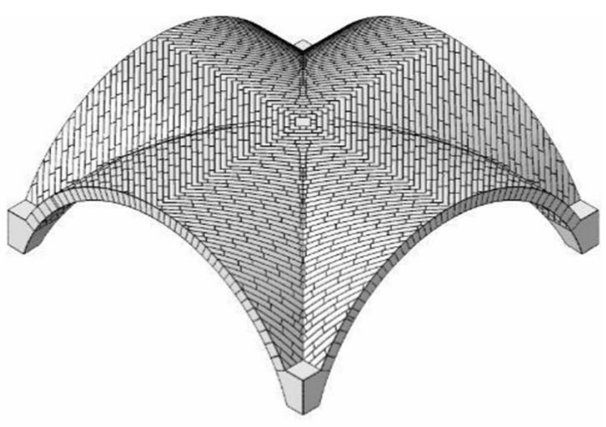

(b)

Fig. 2 Radial (a) and diagonal (b) masonry pattern 
More in detail, in the case of radial pattern the longitudinal courses between bricks are normal to the ring arches, while, in the case of diagonal pattern they are oriented at $45^{\circ}$. In the case of radial courses, the vault is not stable until completion of construction, like in the case of an arch (not stable until the key stone is positioned). When this pattern is used, good interlocking should be provided at the intersection of the caps, in order to strengthen the groins and prevent cracking along these lines. On the contrary, when the diagonal pattern is employed every new brick course is self-supporting with an arch-like curvature, as described in Alforno et al. (2020). However, in contrast to some other vault's geometries (e.g.: barrel vaults), cross vaults cannot be built without any provisional support when using this pattern: as a matter of fact, centering is required in order to support the diagonal arches during construction, whereas the rest of the surfaces can be built arranging selfsupporting courses to be spanned conveniently between the centering arches. A continuous masonry fabric is created through the neighbouring caps over the groins, thus avoiding a continuous joint along the diagonal arches. The diagonally tilted courses are seamed in the ridge of every cap. The spatial position of the bed-joint planes is supposed to be normal to the curve of the groin: however, this rule leads to a radial inclination of the bed joints and consequently to an angle of every bed-joint plane with respect to the preceding one. Therefore, blocks are arranged so that each of them is perpendicular to the intrados surface. In doing so, bed joints of every block will be normal to the surface of the intrados and of constant thickness. However, they will not lie on a single plane, but on a doubly curved surface, as can be seen in Fig. 3.

Figure 4 shows the details of the geometry and the discretization into bricks (the vault with radial brick pattern is reported as an example).

The discretization of the solid volume of the vaults is conducted by means of a simplified micro-modelling approach which allows for the detailed definition of the brick pattern (Lourenço et al. 1995). Such a method consists in the assemblage of a series of elastic blocks connected with zero-thickness interfaces endowed with proper tangential and normal mechanical properties. This method has already been adopted and validated by the authors in previous researches (Alforno et al. 2020, 2021a, b), where a detailed description of the adopted numerical approach is provided. Herein, the main features are briefly recalled. In the present model, the mortar thickness is included within the dimension of the masonry blocks and the mechanical parameters adopted for both blocks and interfaces are set to take into account the role of the mortar joints. Interfaces are assumed as rigid in compression, by the introduction of a high value of normal stiffness $k_{n}$, so that $\sigma_{c}=k_{n} \cdot \delta_{n}$, where $\sigma_{c}$ is the compressive stress and $\delta_{n}$ is the displacement occurring after the normal contact between two nodes of the model. The
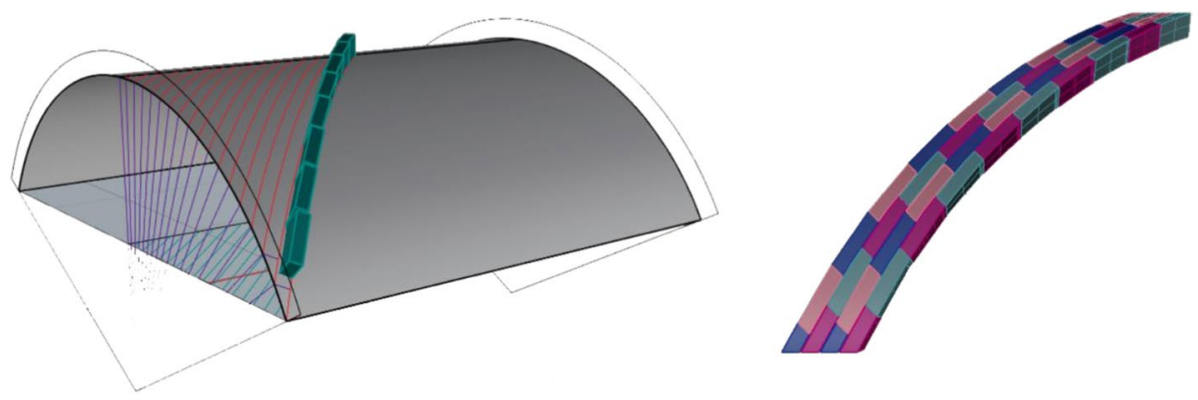

Fig. 3 Rhino model of a diagonal brick course on a curved intrados surface (Alforno et al. 2020) 


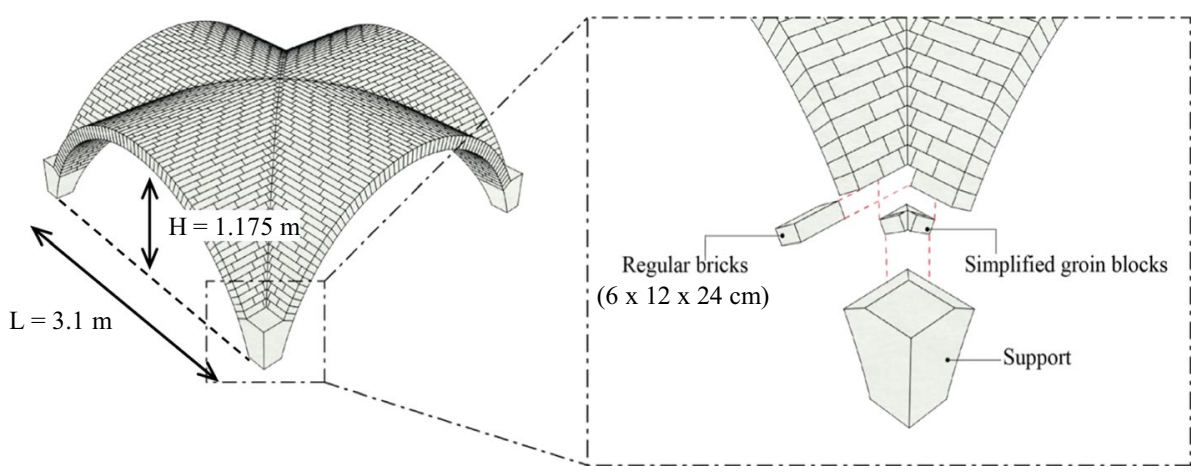

Fig. 4 Geometry and discretization of the vault

Table 1 Mechanical properties of blocks and interfaces

\begin{tabular}{llllll}
\hline Blocks & & & \multicolumn{2}{l}{ Interfaces } \\
\cline { 1 - 2 }$\left(\mathrm{kg} / \mathrm{m}^{3}\right)$ & $E(\mathrm{MPa})$ & $\nu(-)$ & & $\mu(-)$ & $k_{n}(\mathrm{MPa} / \mathrm{mm})$ \\
\hline 1800 & 1200 & 0.2 & & 0.5 & 5 \\
\hline
\end{tabular}

definition of contacts in tangential direction follows classical frictional behavior, neglecting the contribution of cohesion as suggested by D'Altri et al. (2019), i.e., $\tau_{f r}=-\sigma_{c} \cdot \mu$, where $\tau_{f r}$ is the tangential stress, and $\mu$ the static friction coefficient. This assumption is justified by the fact that historic masonry is often characterized by very low cohesive mortar, in particular in case of degraded lime-mortar. The mechanical parameters adopted in the model are reported in Table 1.

To simulate a rigid normal contact, the stiffness of interfaces $k_{n}$ has been calibrated in order to be almost infinite in compression.

Structural models of the vaults are generated through the software Abaqus (2019). The finite elements used for the bricks are linear hexahedra of $30 \mathrm{~mm}$ size, resulting in a maximum brick to element size ratio equal to 0.5 . Every brick is divided in 64 elements. The blocks along the diagonal arches and the abutments of the cross vault are modelled using second order tetrahedra of the same approximate size. For the hexahedral elements the meshing technique is of structured type, while for the tetrahedra a free meshing algorithm has been adopted. Numerical simulations are carried out by adopting dynamic implicit analysis to investigate the structural behaviour under quasi-static regime, in order to control and stabilize the numerical convergence of the solution. Geometrical nonlinearities are taken into account.

\subsection{Load and boundary conditions}

The seismic performance of the cross vault is analysed through pushover analyses, by applying a monotonically increasing horizontal acceleration to the structure. A uniform acceleration profile has been applied to generate horizontal forces proportional to mass regardless of elevation, as prescribed by Eurocode 8, Sect. 4.3.3, 4.2.2 (Comité Européen de Normalisation 2004). The uniform profile is chosen instead of the modal profile in order to guarantee the same load condition to both vaults. Two different directions of the seismic acceleration, parallel and diagonal to the axes of symmetry of the vault, are 


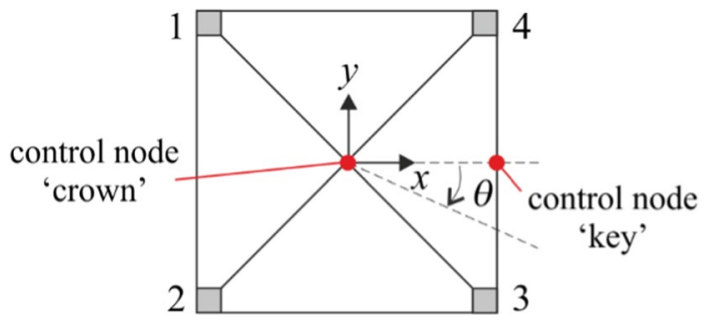

Fig. 5 Push-over analysis: lateral load direction and control nodes

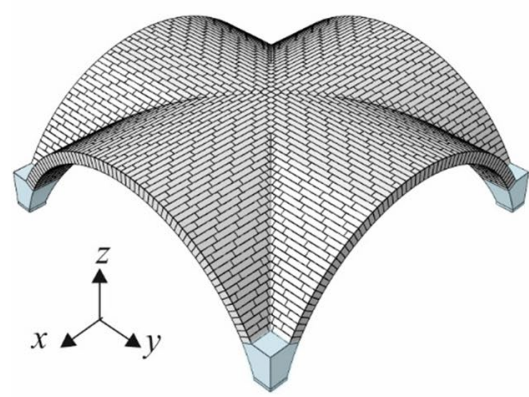

(a)

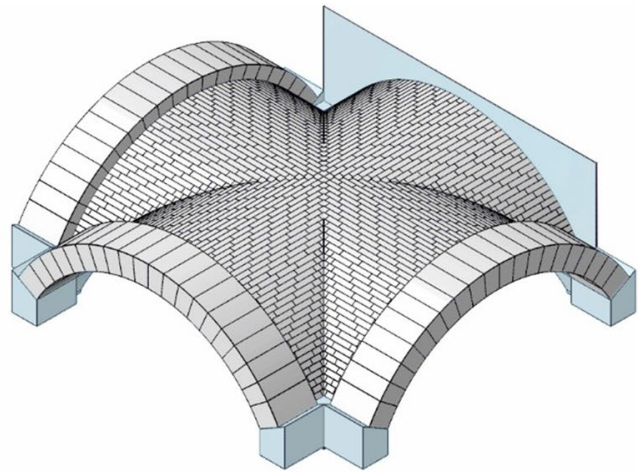

(b)

Fig. 6 Boundary conditions: no confinement (NC) (a) and boundary arches (AR) (b)

considered. They are defined by the angle $\theta$, measured with respect to the $x$-direction, and corresponding to $\theta=0^{\circ}$ and $\theta=45^{\circ}$ (Fig. 5). The analysis is divided in two steps: first the gravitational acceleration is applied, then the horizontal acceleration is added.

Two different boundary conditions are considered in the simulations: in the first one the vault is confined by a rigid wall between abutments 1 and 4 and by lateral ARches (AR) on the other three sides, while in the second one it is Not Confined (NC) (Fig. 6). The boundary arches are $27 \mathrm{~cm}$ thick (i.e., about twice the vault thickness) and $50 \mathrm{~cm}$ wide. Their mechanical properties are the same used for blocks and described in the previous section. The rigid wall is simulated by means of a fictitious rigid plane, whose external surfaces are restrained against out-of-plane displacements and whose internal surfaces are connected to the head arches of the vault by zero-thickness interfaces with the same mechanical properties used for defining the block-to-block contacts. The head arches of the vault can detach from the boundary structures, while they are prevented to compenetrate them. This means that normal compressive forces as well as shear forces can arise along the planes of the boundary structures, while no tension forces can develop. Shear forces depend on the normal compressive forces, according to the Mohr-Coulomb criterion. Finally, in both boundary conditions, all the nodes at the base of the piers and boundary arches are rigidly constrained. 


\subsection{Numerical analyses}

A numerical study is conducted with the aim of highlighting two main effects on the seismic response of the cross vault, namely the effect of the brick pattern and of the confinement. Since previous studies conducted by the authors (Alforno et al. 2020) have demonstrated that diagonal vaults are not stable without confinement, the effect of the brick pattern (radial and diagonal) is assessed regarding AR confined vaults only. Conversely, the effect of the lateral constraints is assessed just for the radial vault. Table 2 reports the list of the performed simulations. The results will be commented in the following sections.

\section{Results}

\subsection{Effects of brick pattern}

In Fig. 7 and 8, the deformed shapes at collapse of the diagonal and radial vaults for $\theta=$ $0^{\circ}$ and $\theta=45^{\circ}$ are represented, respectively. In the lateral views, they are plotted without boundary arches, to better highlight the collapse mechanism of the vaults. The direction of applied horizontal acceleration is indicated by red arrows in the axonometric views. It can be observed that the two vaults behave quite differently:

- When $\theta=0^{\circ}$, the radial vault collapses due to the formation of a global mechanism characterized by four parallel hinges normal to the direction of the seismic action. On the contrary, the diagonal vault undergoes a local failure, which involves only one cap.

- When the angle of the seismic action is $\theta=45^{\circ}$, the deformed shapes show an almost symmetric collapse mechanism with respect to the groin along the direction of imposed acceleration on both radial and diagonal vaults. Also in this case, the radial vault is mainly interested by a global collapse mechanism, while the diagonal vault undergoes local failures. Specifically, in the radial vault the collapse is due to the formation of parallel hinges along the bed joints, and to a local failure in the region along the groins, where the sliding and detachment of a few bricks take place. The diagonal vault shows a quite different crack pattern characterized by local failures at the head arches of two opposite caps. The local collapses of the diagonal vault can be explained by the stabilizing role of the boundary arches. Actually, it has been demonstrated (Alforno et al. 2021b) that the vault with the diagonal pattern thrusts along the head arches, and its stability (under self-weight) is not possible without lateral confinement. Therefore,

Table 2 Summary of the parametric analyses

\begin{tabular}{llll}
\hline ID & Pattern & $\begin{array}{l}\text { Boundary condi- } \\
\text { tions }\end{array}$ & $\begin{array}{l}\text { Seismic accelera- } \\
\text { tion direction } \theta \\
\left({ }^{\circ}\right)\end{array}$ \\
\hline 1 & R & AR & 0 \\
2 & D & AR & 0 \\
3 & R & AR & 45 \\
4 & D & AR & 45 \\
5 & R & NC & 0 \\
6 & R & NC & 45 \\
\hline
\end{tabular}




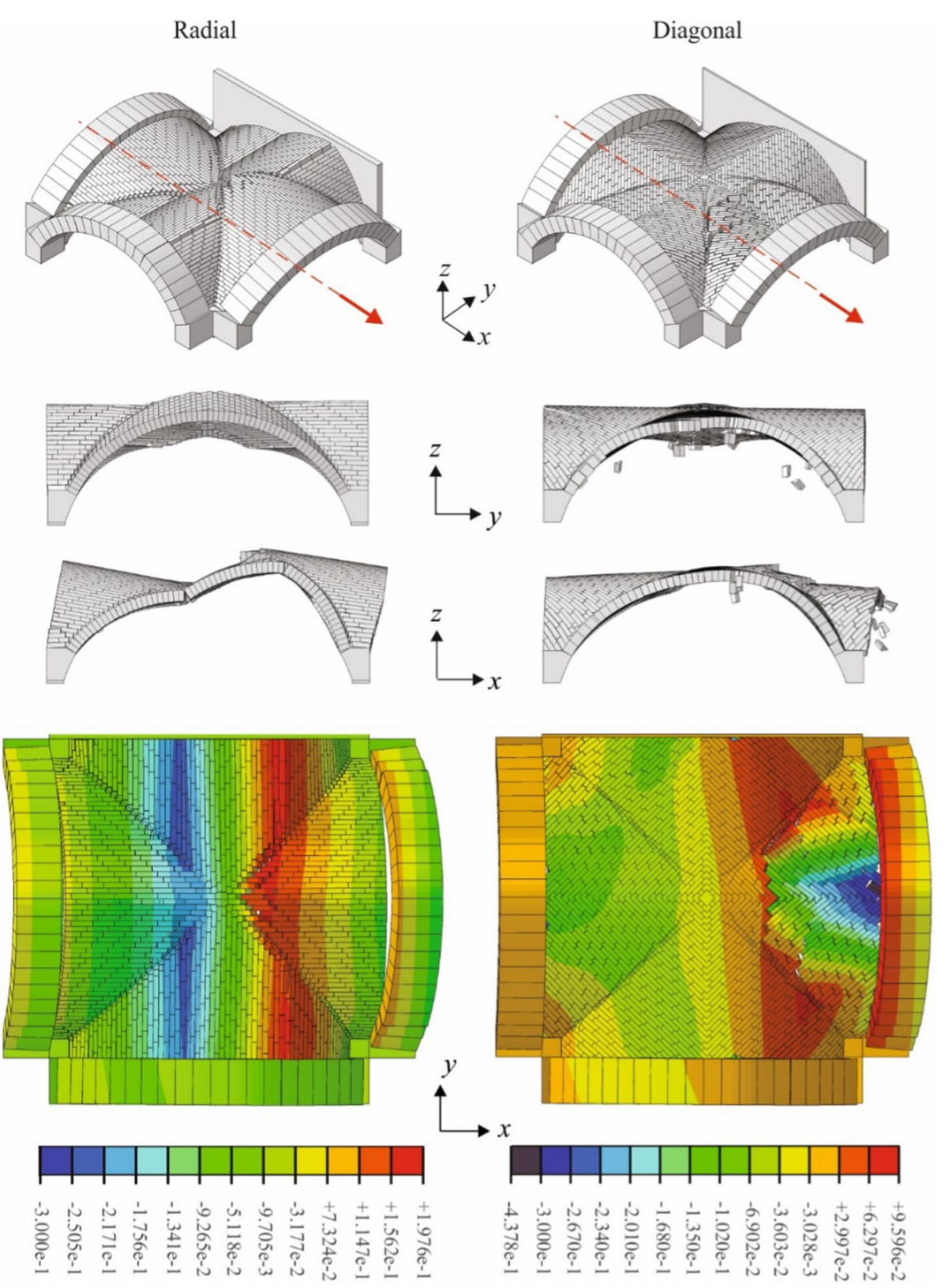

Fig. 7 Collapse shapes in Pushover analysis for $\theta=0^{\circ}$ : axonometric view (first row), $y-z$ plane view (second row), $x-z$ plane view (third row), planar view with contour plot of $u_{z}$ displacement [m] (fourth row) 

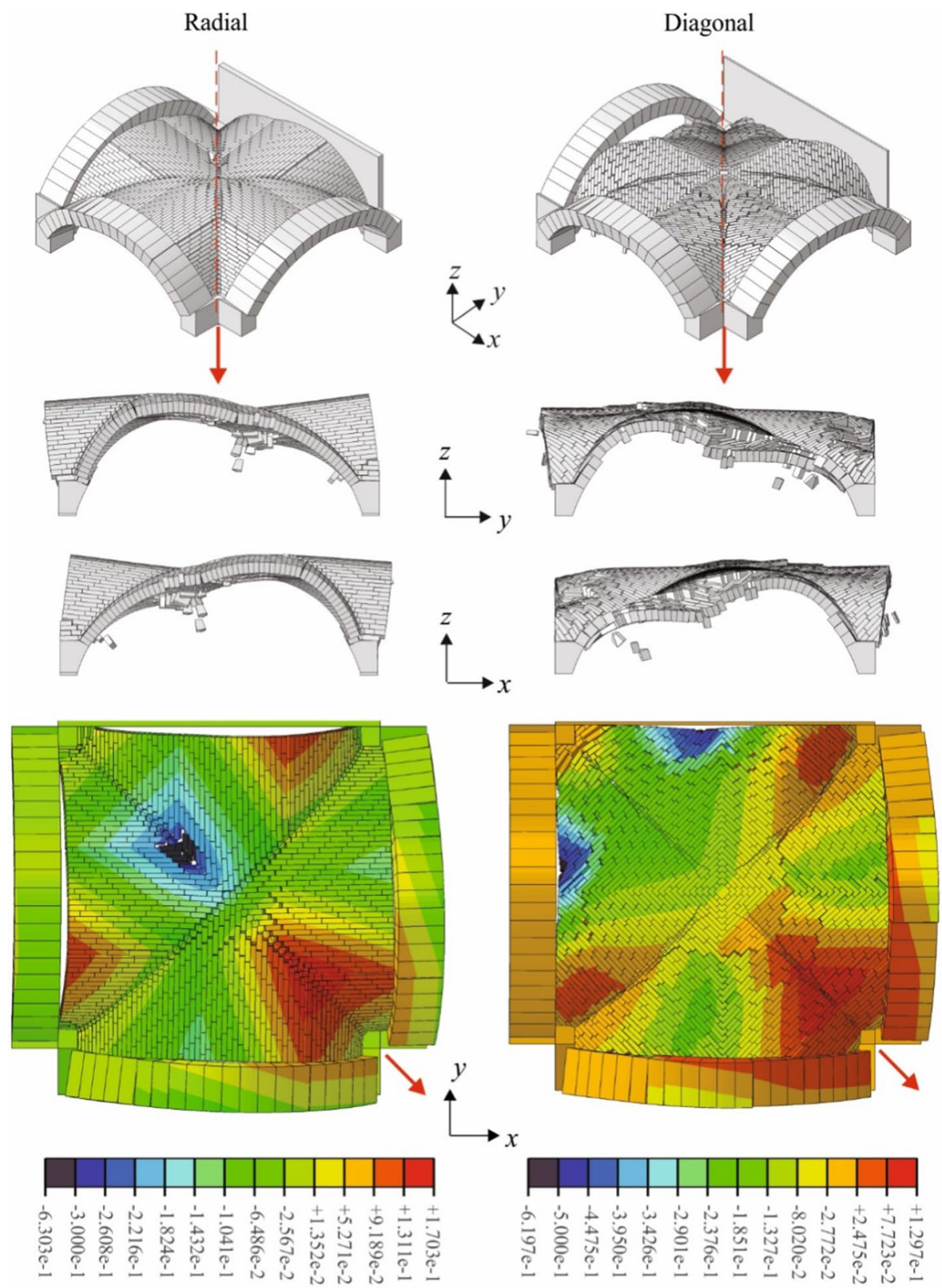

Fig. 8 Collapse shapes in Pushover analysis for $\theta=45^{\circ}$ : axonometric view (first row), $y-z$ plane view (second row), $x-z$ plane view (third row), planar view with contour plot of $u_{z}$ displacement [m] (fourth row) 


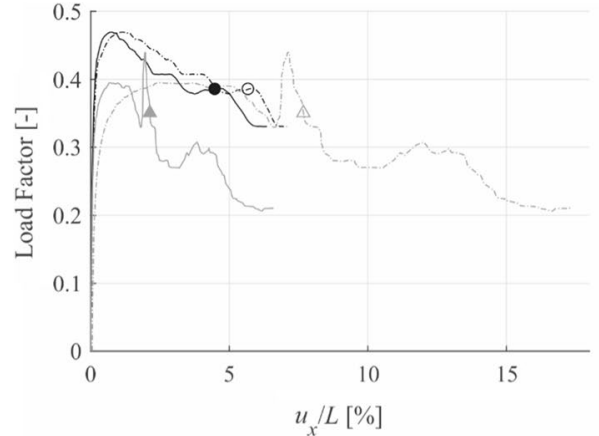

(a)

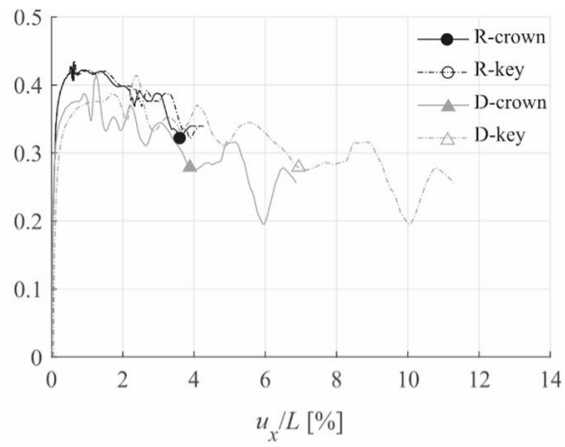

(b)

Fig. 9 Capacity curves of confined radial $(R)$ and diagonal $(D)$ cross vaults for $\theta=0^{\circ}(\mathbf{a})$ and $\theta=45^{\circ}(\mathbf{b})$

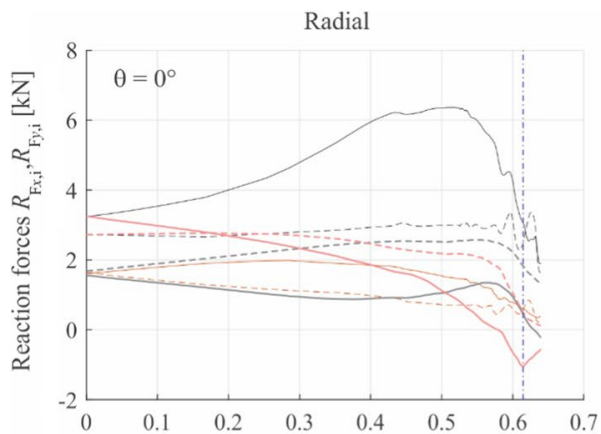

(a)

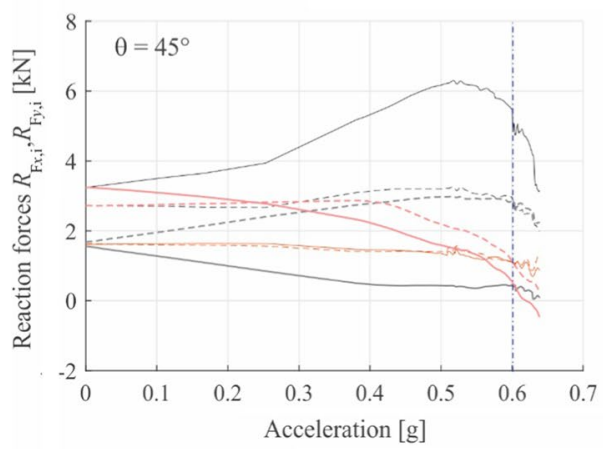

(c)

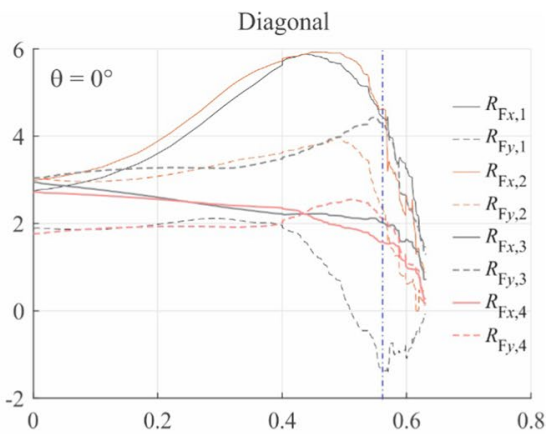

(b)

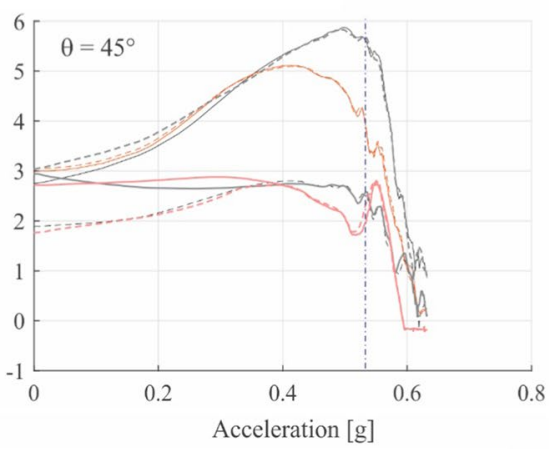

(d)

Fig. 10 Reaction forces $R_{F x, i}$ and $R_{F y, i}$ at the $i$-th abutment vs. horizontal acceleration

when the head arches detach from the webs due to the imposed horizontal acceleration, the vault undergoes a local collapse.

Figure 9 plots the Load Factor $(L F)$ vs. the normalised displacement $u_{x} / L$ of both considered masonry patterns for $\theta=0^{\circ}$ and $\theta=45^{\circ}$. Two control nodes have been chosen: one 
Table 3 Critical quantities used for comparison between brick patterns

\begin{tabular}{llllllll}
\hline Pattern & $L F_{\max }(-)$ & $u_{c, \text { rrown }}(\mathrm{m})$ & $u_{c, \text { key }}(\mathrm{m})$ & $K_{\mathrm{el}}(\mathrm{N} / \mathrm{m}) \cdot 10^{6}$ & $u_{60}(\mathrm{~m})$ & $u_{80}(\mathrm{~m})$ & $u_{80} / u_{60}(-)$ \\
\hline $\begin{array}{l}\text { Radial } \\
\theta=0^{\circ}\end{array}$ & 0.469 & 0.131 & 0.169 & 10.05 & 0.0020 & 0.158 & 78.9 \\
$\begin{array}{l}\text { Diagonal } \\
\theta=0^{\circ}\end{array}$ & 0.394 & 0.064 & 0.233 & 8.59 & 0.0019 & 0.072 & 37.02 \\
$\begin{array}{l}\text { Radial } \\
\theta=45^{\circ}\end{array}$ & 0.419 & 0.109 & 0.118 & 12.12 & 0.0015 & 0.107 & 71.94 \\
$\begin{array}{l}\text { Diagonal } \\
\theta=45^{\circ}\end{array}$ & 0.374 & 0.118 & 0.211 & 11.07 & 0.0014 & 0.150 & 68.45 \\
\hline
\end{tabular}

Table 4 Variation of peak load factor, elastic stiffness and ductility between the diagonal and the radial vault

\begin{tabular}{llll}
\hline Force direction & $\Delta L F_{\max }(\%)$ & $\Delta K_{\mathrm{el}}(\%)$ & $\Delta\left(u_{80} / u_{60}\right)(\%)$ \\
\hline$\theta=0^{\circ}$ & -15.99 & -14.52 & -53.08 \\
$\theta=45^{\circ}$ & -10.73 & -8.66 & -4.85 \\
\hline
\end{tabular}

is at the crown of the vault and the other is at the key of the head arch of one cap (Fig. 5). The load factor $L F$ is obtained by normalizing the sum of the horizontal reaction forces at the abutments $R_{F}$ in the direction of the applied seismic action to the vault's weight $W$ (including the weight of the boundary arches). The markers in Fig. 9 are referred to the values of displacement in $x$ direction $u_{c \text {,crown }}$ and $u_{c \text {,key }}$ corresponding to the activation of the collapse mechanism. These values are difficult to be identified on the capacity curves, therefore both $x$ and $y$ horizontal reaction forces at each support have been plotted in Fig. 10 (see Fig. 5 for support numbers). The collapse mechanism is thus identified by referring to a sudden decrease of force on the force-acceleration curves, which is denoted in Fig. 10 by vertical dash-dot lines. Finally, it is possible to identify the displacement of the control nodes which corresponds to the acceleration that activates the collapse mechanism and the corresponding markers are reported in Fig. 9.

In order to compare the capacity curves, the following quantities have been identified:

- $L F_{\max }$, peak value of the load factor;

- $u_{c, \text { crown }}$, maximum horizontal displacement reached at the crown of the vault before the collapse;

- $u_{c, \text { key }}$, maximum horizontal displacement reached at the key of one head arch before the collapse;

- $K_{\mathrm{el}}$, elastic stiffness, calculated as the ratio $R_{60} / u_{60}$ between the $60 \%$ of $R_{\mathrm{F}, \max }$ and the corresponding displacement at the crown $u_{60}$, where $R_{\mathrm{F}, \max }=L F_{\max }$. $W$;

- $u_{80} / u_{60}$, ductility parameter where $u_{80}$ is the settlement at the crown corresponding to $R_{80}$, i.e., to a post-peak $20 \%$ reduction of $R_{\max }$.

Table 3 reports the values of the above-defined quantities, while Table 4 reports the variations in percentage between the diagonal and radial pattern. In particular, the table 
reports the variations in terms of $\Delta Q=\left(Q_{\text {diagonal }}-Q_{\text {radial }}\right) / Q_{\text {radial }} \cdot 100$, where $Q$ is the generic quantity.

The two vaults have quite similar strength and stiffness, with variations below $20 \%$. However, the diagonal vault is always less resistant and more deformable than the radial one. The largest difference between the two patterns is in terms of ductility, in particular for $\theta=0^{\circ}$. Such a difference can be explained by observing the collapse modes of the two vaults (Fig. 7): the radial vault experiences a global collapse involving all the caps of the vault, while the collapse of the diagonal vault is partial and involves one cap only, the rest of the vault remaining stable. This different behaviour is also visible in the load displacement curves in Fig. 9, by looking at the values of displacement of the control nodes. As a matter of fact, in the radial vault, the horizontal displacement of the head arch is only 1.16 times greater than the horizontal displacement of the crown, whereas in the diagonal vault it is 2.65 times greater.

\subsection{Effects of boundary conditions}

Figures 11 and 12 show the deformed shapes of the radial vault for the two boundary conditions considered. It is clearly visible that, for $\theta=0^{\circ}$, the collapse shape is almost not influenced by the presence of lateral confinement (AR), since both models show similar crack pattern (parallel hinges normal to the $x$-axis) and order of magnitude of vertical displacements. This consideration is also true for $\theta=45^{\circ}$, where hinges parallel to the directrix of each cap are visible and a local collapse takes place along one groin.

Even though lateral boundary conditions do not substantially change the collapse shapes, they provide a great influence in terms of maximum resistance and elastic stiffness of the structure. This is visible in Fig. 13, which plots the load-displacement curves for $\theta=$ $0^{\circ}$ and $\theta=45^{\circ}$, respectively.

In Table 5 the values of the critical quantities of the load-displacement curves are reported, while Table 6 shows the variations between confined (AR) and not confined (NC) vaults $\left(\Delta Q=\left(Q_{\mathrm{AR}}-Q_{\mathrm{NC}}\right) / Q_{\mathrm{NC}} \cdot 100\right.$, where $Q$ is the generic quantity). Also in this case, the values of the critical displacements in $x$ direction $u_{c \text {,crown }}$ and $u_{c \text {,key }}$ are obtained by analysing the curves of the reaction forces at the abutments shown in Fig. 14, in which is possible to identify a sudden drop of force corresponding to the collapse of the structure. On the basis of the above-defined quantities, the two vaults have quite different capacity in terms of peak load factor. As a matter of fact, the value of maximum load factor increases of about $51 \%$ if the vault is confined with the arches when $\theta=0^{\circ}$, and of about $23 \%$ if $\theta=$ $45^{\circ}$. Also the values of elastic stiffness differ vastly, as well as ductility. Specifically, for $\theta$ $=0^{\circ}$, the confined vault (AR) is much stiffer (about 4 times) and ductile (about 2.5 times) than the unconfined one. This is confirmed also for $\theta=45^{\circ}$.

From these considerations it is possible to state that the AR boundary condition provides a beneficial influence on masonry cross vaults. Therefore, if they are not taken into account during a simulation, the values of peak load factor, elastic stiffness and ductility would be underestimated, whereas the collapse mechanisms would not be affected. 

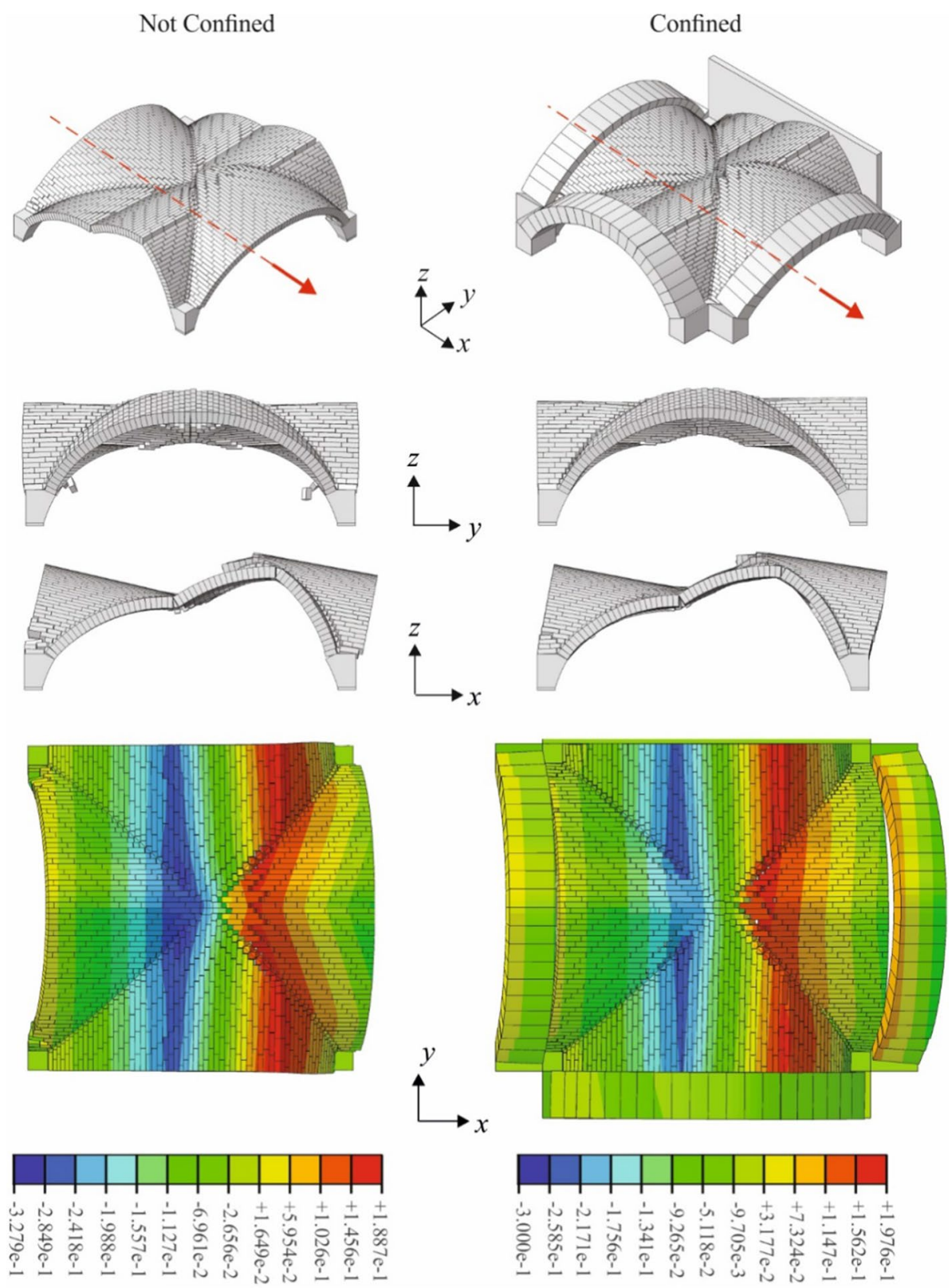

(a)

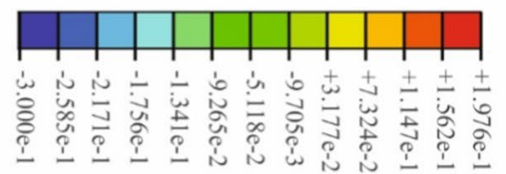

(b)

Fig. 11 Collapse shapes in Pushover analysis for $\theta=0^{\circ}$ : axonometric view (first row), $y-z$ plane view (second row), $x-z$ plane view (third row), planar view and contour plot of $u_{z}$ displacement [m] (fourth row) 

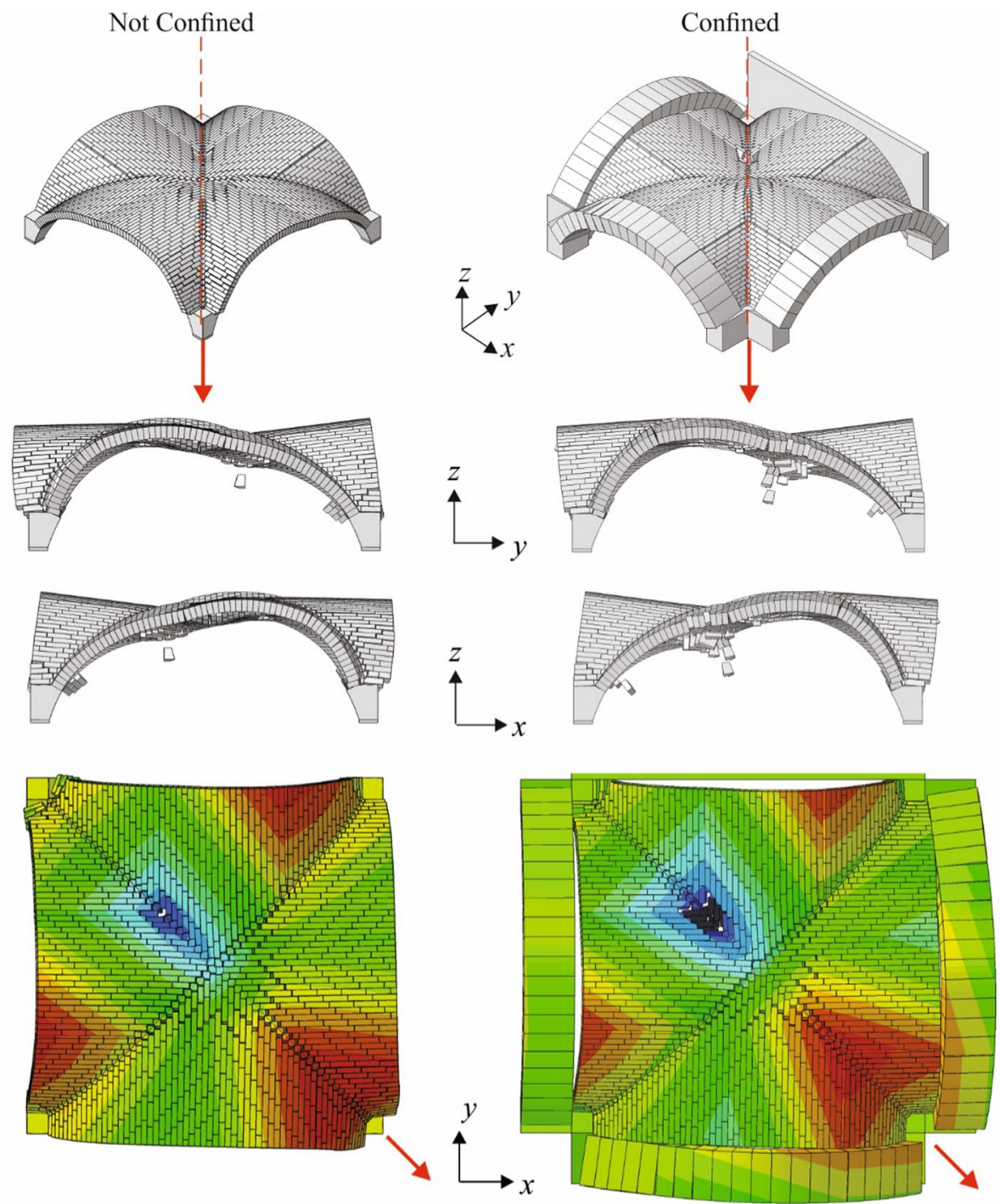

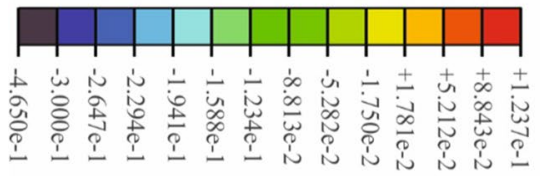

(a)

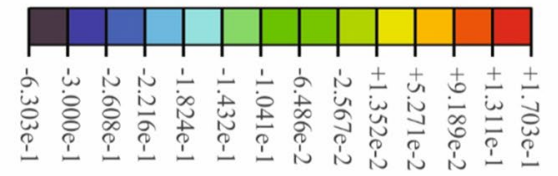

(b)

Fig. 12 Collapse shapes in Pushover analysis for $\theta=45^{\circ}$ : axonometric view (first row), $y-z$ plane view (second row), $x-z$ plane view (third row), planar view and contour plot of $u_{z}$ displacement [m] (fourth row) 


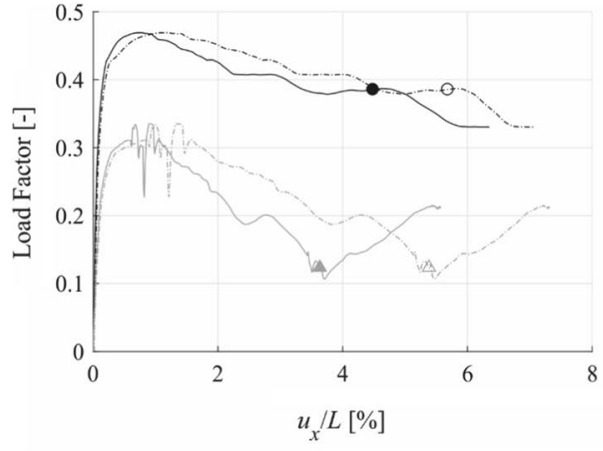

(a)

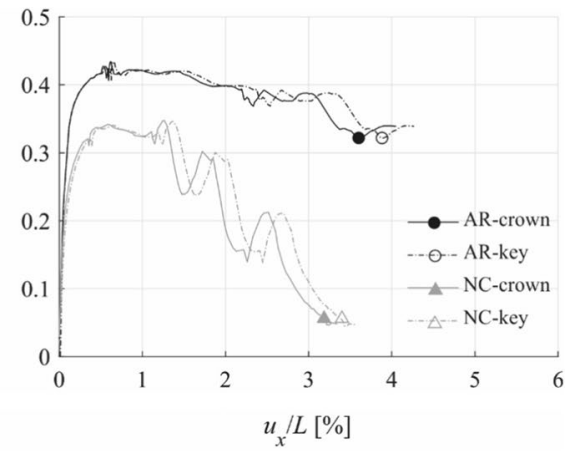

(b)

Fig. 13 Capacity curves of confined and unconfined radial cross vaults for $\theta=0^{\circ}$ (a) and $\theta=45^{\circ}$ (b)

Table 5 Critical quantities used for comparison between boundary conditions

\begin{tabular}{llllllll}
\hline Boundary condition & $L F_{\max }(-)$ & $u_{c, \text { crown }}(\mathrm{m})$ & $u_{c, \text { key }}(\mathrm{m})$ & $K_{\mathrm{el}}(\mathrm{N} / \mathrm{m}) \times 10^{6}$ & $u_{60}(\mathrm{~m})$ & $u_{80}(\mathrm{~m})$ & $u_{80} / u_{60}(-)$ \\
\hline $\mathrm{AR} \theta=0^{\circ}$ & 0.469 & 0.131 & 0.169 & 10.05 & 0.0020 & 0.158 & 78.9 \\
$\mathrm{NC} \theta=0^{\circ}$ & 0.311 & 0.112 & 0.166 & 1.92 & 0.0025 & 0.091 & 22.4 \\
$\mathrm{AR} \theta=45^{\circ}$ & 0.419 & 0.109 & 0.118 & 12.12 & 0.0015 & 0.107 & 71.94 \\
$\mathrm{NC} \theta=45^{\circ}$ & 0.342 & 0.088 & 0.09 & 2.62 & 0.0021 & 0.048 & 16.66 \\
\hline
\end{tabular}

Table 6 Variation of peak load factor, elastic stiffness and ductility between confined and not confined vaults

\begin{tabular}{llll}
\hline Force direction & $\Delta L F_{\max }(\%)$ & $\Delta K_{\mathrm{el}}(\%)$ & $\Delta\left(u_{80} / u_{60}\right)(\%)$ \\
\hline$\theta=0^{\circ}$ & +50.80 & +423.4 & +252.2 \\
$\theta=45^{\circ}$ & +22.51 & +362.6 & +331.8 \\
\hline
\end{tabular}

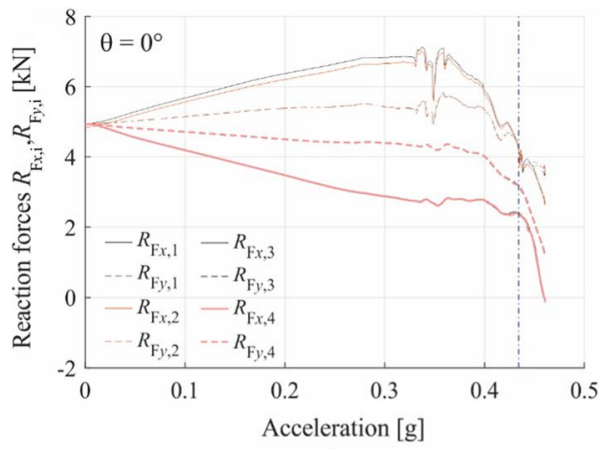

(a)

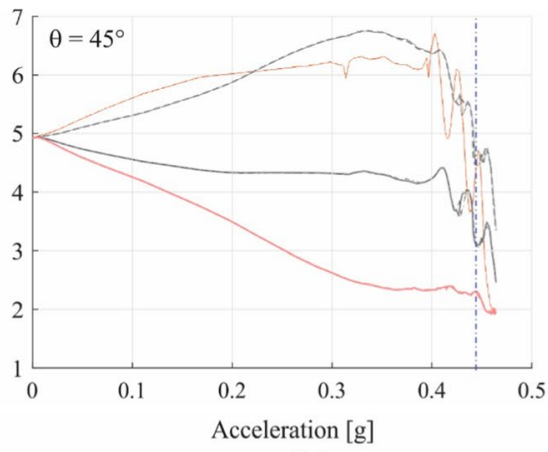

(b)

Fig. 14 Reaction forces $R_{\mathrm{F} x, i}$ and $R_{\mathrm{F} y, i}$ at the $i$-th abutment vs. horizontal acceleration for $\theta=0^{\circ}(\mathbf{a})$ and $45^{\circ}$ (b) 


\section{Conclusions}

In this paper the results of parametric analyses on the seismic response of masonry cross vaults are presented. The geometry of an ideal vault is considered taking into account its detailed brick pattern. Two different brick patterns are considered, i.e., radial and diagonal bed joints, and two different lateral boundary conditions are applied on the radial vault, namely vault without confinement (NC) and confined with lateral arches (AR).

The FEM simplified micro-modelling approach is adopted for the discretization of the volume of the structure. Linear elastic behaviour is assumed for the expanded masonry blocks, while the interfaces are assigned tangential frictional behaviour and normal rigid compressive contact. Free detachment is allowed under traction. Static non-linear analyses are performed, assuming two different directions of the seismic input in the horizontal plane, namely $0^{\circ}$ and $45^{\circ}$.

The results show that the brick pattern greatly influences the seismic response in terms of collapse mechanism. In general, radial vaults are characterized by global failures, while diagonal vaults undergo local failures, whichever the direction of the seismic action. The influence of the brick pattern is limited in terms of seismic load capacity and elastic stiffness, while it highly affects the ductility. In particular, diagonal bed joints are able to provide the vault with almost twice displacement capacity than radial ones. The presence of lateral arches provides the radial vault with greater resistance, elastic stiffness and ductility, even though it does not affect significantly the failure mode. These findings highlight the importance of taking into account all constructive aspects in the modelling of masonry vaults, so as to avoid the underestimation of their capacity in terms of peak load factor or maximum displacement.

Author contributions All authors contributed equally.

Funding Open access funding provided by Politecnico di Torino within the CRUI-CARE Agreement.

Data availability Not applicable.

Code availability Not applicable.

\section{Declarations}

Conflict of interest There are not conflicts of interests in this work.

Open Access This article is licensed under a Creative Commons Attribution 4.0 International License, which permits use, sharing, adaptation, distribution and reproduction in any medium or format, as long as you give appropriate credit to the original author(s) and the source, provide a link to the Creative Commons licence, and indicate if changes were made. The images or other third party material in this article are included in the article's Creative Commons licence, unless indicated otherwise in a credit line to the material. If material is not included in the article's Creative Commons licence and your intended use is not permitted by statutory regulation or exceeds the permitted use, you will need to obtain permission directly from the copyright holder. To view a copy of this licence, visit http://creativecommons.org/licenses/by/4.0/.

\section{References}

Abaqus Theory Manual (2019) Dassault Systemes 
Alforno M, Venuti F, Monaco A (2020) The structural effects of micro-geometry on masonry vaults. Nexus Netw J 22:1237-1258

Alforno M, Monaco A, Venuti F, Calderini C (2021a) Validation of simplified micro-models for the static analysis of masonry arches and vaults. Int J Architect Heritage 15:1196-1212

Alforno M, Venuti F, Monaco A, Calderini C (2021b) Numerical investigation of the influence of constructive aspects on the structural behaviour of masonry cross vaults. Int J Architect Heritage. https://doi. org/10.1080/15583058.2021.1992534

Bertolesi E, Adam JM, Rinaudo P, Calderón PA (2019) Research and practice on masonry cross vaults: a review. Eng Struct 180:67-88

Block P, Lachauer L (2014) Three-dimensional (3D) equilibrium analysis of gothic masonry vaults. Int J Architect Heritage 8(3):312-335

Carfagnini C, Baraccani S, Silvestri S, Theodossopoulos D (2018) The effects of in-plane shear displacements at the springings of Gothic cross vaults. Constr Build Mater 186:219-232

Cattari S, Resemini S, Lagomarsino S (2008) Modelling of vaults as equivalent diaphragms in 3D seismic analysis of masonry buildings. In Structural analysis of historic construction: preserving safety and significance, two volume set. CRC Press, pp 537-544

Clemente P (1998) Introduction to dynamics of stone arches. Earthq Eng Struct Dyn 27:513-522

Comité Européen de Normalisation (2004) Eurocode 8: design of structures for earthquake resistance. Part I: general rules, seismic actions and rules for buildings EN1998-I, CEN, Brussels

D’Altri AM, Sarhosis V, Milani G, Rots J, Cattari S, Lagomarsino S, Sacco E, Tralli A, Castellazzi G, De Miranda S (2019) Modeling strategies for the computational analysis of unreinforced masonry structures: review and classification. Arch Comput Methods Eng 27:1153-1185

D’Ayala DF, Tomasoni E (2011) Three-Dimensional analysis of masonry vaults using limit state analysis with finite friction. Int J Architect Heritage 5(2):140-171

De Lorenzis L, DeJong M, Ochsendorf J (2007) Failure of masonry arches under impulse base motion. Earthq Eng Struct Dyn 36:2119-2136

De Luca A, Giordano A, Mele E (2004) A simplified procedure for assessing the seismic capacity of masonry arches. Eng Struct 26:1915-1929

DeJong M, De Lorenzis L, Adams S, Ochsendorf J (2008) Rocking stability of masonry arches in seismic regions. Earthq Spectra 24:847-865

Foti D, Vacca V, Facchini I (2018) DEM modelling and experimental analysis of the static behavior of a dry-joints masonry cross vaults. Constr Build Mater 170:111-120

Gaetani A, Bianchini N, Lourenço PB (2021) Simplified micro-modelling of masonry cross vaults: stereotomy and interface issues. Int J Masonry Res Innov 6(1):97-125

Gaetani A, Lourenço PB, Monti G, Milani G (2017) A parametric investigation on the seismic capacity of masonry cross vaults. Eng Struct 148:686-703

Gaetani A, Monti G, Lourenço PB, Marcari G (2016) Design and analysis of cross vaults along history. Int J Architect Heritage 10:841-856

Giamundo V, Sarhosis V, Lignola GP, Sheng Y, Manfredi G (2014) Evaluation of different computational modelling strategies for the analysis of low strength masonry structures. Eng Struct 73:160-169

Lengyel G (2017) Discrete element analysis of gothic masonry vaults for self-weight and horizontal support displacement. Eng Struct 148:195-209

Lengyel G, Németh RK (2019) The mechanical behavior of ribs in masonry groin vaults subjected to seismic load. Int J Architect Heritage 13(6):886-900

Lourenço PB, Rots J, Blaauwendraad J (1995) Two approaches for the analysis of masonry structures: micro and macro-modeling. HERON 40(4):313-340

Marseglia PS, Micelli F, Aiello MA (2020) Analysis of equivalent diaphragm vault structures in masonry construction under horizontal forces. Heritage 3(3):989-1017

McInerney J, Dejong MJ (2015) Discrete element modeling of groin vault displacement capacity. Int J Architect Heritage 9:1037-1049

Milani G, Rossi M, Calderini C, Lagomarsino S (2016) Tilting plane tests on a small-scale masonry cross vault: experimental results and numerical simulations through a heterogeneous approach. Eng Struct 123:300-312

Milani G, Valente M, Alessandri C (2017) The narthex of the Church of the nativity in Bethlehem: a nonlinear finite element approach to predict the structural damage. Comput Struct 207:3-18

Milani G, Valente M, Fagone M, Rotunno T, Alessandri C (2019) Advanced non-linear numerical modeling of masonry groin vaults of major historical importance: St John Hospital case study in Jerusalem. Eng Struct 194:458-476

Mousavian E, Casapulla C (2019) The role of different sliding resistances in limit analysis of hemispherical masonry domes. Frattura Ed Integrità Strutturale 14(51):336-355 
Nodargi NA, Bisegna P (2021) A finite difference method for the static limit analysis of masonry domes under seismic loads. Meccanica. https://doi.org/10.1007/s11012-021-01414-3

Olmati P, Gkoumas K, Bontempi F (2019) Simplified FEM modelling for the collapse assessment of a masonry vault. Frattura Ed Integrità Strutturale 13(47):141-149

Oppeneheim IJ (1992) The masonry arch as a four-link mechanism under base motion. Earthq Eng Struct Dyn 21:1005-1017

Palmisano F, Perilli P (2017) Forensic investigations of collapses of buildings in "Aggregate": lesson learnt from a meaningful case study. Struct Eng Int 27(3):394-401

Riveiro B, Morer P, Arias P, De Arteaga I (2011) Terrestrial laser scanning and limit analysis of masonry arch bridges. Constr Build Mater 25(4):1726-1735

Rossi M, Calderini C, Lagomarsino S (2016) Experimental testing of the seismic in-plane displacement capacity of masonry cross vaults through a scale model. Bull Earthq Eng 14:261-281

Rossi M, Calderini C, Roselli I, Mongelli M, De Canio G, Lagomarsino S (2020) Seismic analysis of a masonry cross vault through shaking table tests: the case study of the Dey Mosque in Algiers. Earthq Struct 18(1):57-72

Sarhosis V, Milani G, Formisano A, Fabbrocino F (2018) Evaluation of different approaches for the estimation of the seismic vulnerability of masonry towers. Bull Earthq Eng 16(3):1511-1545

Publisher's Note Springer Nature remains neutral with regard to jurisdictional claims in published maps and institutional affiliations. 